\title{
Characteristics of Graft-Infiltrating \\ Lymphocytes After Human \\ Heart Transplantation \\ HLA Mismatches and the Cellular Immune \\ Response Within the Transplanted Heart
}

\author{
Alice J. Ouwehand, Carla C. Baan, \\ Leonard M. B. Vaessen, Nicolet H. P. M. Jutte, \\ Aggie H. M. M. Balk, Egbert Bos, Frans H. J. Claas, \\ and Willem Weimar
}

\begin{abstract}
The influence of HLA mismatches between donor and recipient on the phenotypes, function, and specificity of T-lymphocyte cultures derived from endomyocardial biopsies was studied in 118 heart transplant recipients In case of HLA-DR mismatches, the majority of the EMB-derived cultures were domınated by $\mathrm{CD}^{+} \mathrm{T}$ cells while, in patients with HLA-A and -B mismatches but without DR mismatches, $\mathrm{CD}^{+} \mathrm{T}$ cells comprised the predominant $\mathrm{T}$-cell subset Cytotoxicity against donor antigens was observed in $75 \%$ of the cultures $\mathrm{A}$ significantly $(p<0005)$ lower proportion of the cultures showed cytotoxicity against HLA-A antigens (36\%) when compared with HLA-B (53\%) or HLA-DR (49\%) An HLA-A2 mismatch elicited a cytotoxic response that was
\end{abstract}

\section{ABBREVIATIONS}

$\begin{array}{ll}\text { CTL } & \text { cytotoxic T lymphocyte } \\ \text { CTLp } & \text { cytotoxic T-lymphocyte precursor } \\ \text { EBV } & \text { Epstein-Barr virus }\end{array}$

EBV Epstein-Barr virus comparable to that found against HLA-B and -DR ant1gens $62 \%$ of the cultures from HLA-A2 mismatched donor-recipient combinations was reactive against A2 A higher number of $A, B$, or DR mismatches resulted in a higher number of cytotoxic cultures directed against these antigens $A$ higher number of HLA-B and -DR mismatches was associated with a lower freedom from rejection Our data indicate that, despite the use of adequate immunosuppressive therapy, the degree of HIA matching plays a crucial role in the immune response against a transplanted heart, resulting in a significant effect on freedom from rejection Human Immunology 39, 233-242 (1994)

EMB

MHC endomyocardial biopsy

major histocompatibility complex phytohemagglutinın
From the Departments of Internal Medictne $I$ ( $A J O, C C B$ $L M B V, N H P M J, W W)$ Cardiology $(A H M M B)$, and Thoract Surgery (E B ), University Hospital Rotterdam-Dijkzigt, Rotterdam, and the Department of Immunobematology and Blood Bank ( $F H J C$ ). Universtity Hospital, Letden, The Netberlands

Address reprint requests to $\operatorname{Dr} A J$ Ouweband, Department of Internal Medictne I, Bd 299, University Hospital Rotterdam-Dijkzigt, Dr Molewaterplein 40, 3015 GD Rotterdam. The Netherlands

Recerved (U) March 5, 1993 accepted September 10, 1993

\section{INTRODUCTION}

Products of the major histocompatibility complex (MHC) play a major role in the immune response against a transplanted organ $[1,2]$ In extensive studies in kidney transplant recipients, a positive effect of HLA matching on graft survival was reported, especially for HLA-B and -DR antigens [3-8] The beneficial effect of DR matching was found to be most evident in the first 
postoperative months, while the effect of matching for HLA-B antigens lasted longer These studies were based on the assumption that all of the HLA alleles had the same antigenic weight Busson and coworkers [9] showed, in kidney transplant recipients with only one incompatible HLA-antigen, that some of the HLA-A antigens were associated with a lower transplant survival than others, while at the B locus, there was no significant difference in survival rate among the different antigens

The importance of HLA matching for heart allograft survival is still debated, mainly because of the limited numbers of patients studied and, more importantly, the low numbers of well-matched grafts performed, as donor hearts are randomly allocated without reference to HLA matching Nevertheless, a beneficial effect of HLA matching has been found for cardiac graft survival [10, 11], the incidence of steroid-resistant rejection [12], or the freedom from rejection of the transplanted heart [13]

Acute allograft rejection is mediated by immunocompetent lymphocytes of the graft recipient that interact with allogeneic determinants expressed on the grafted organ Recognition of both HLA class I and class II allogeneic differences by both helper and cytotoxic $T$ lymphocytes (CTLs) precipitates a cascade of reactions that results in a cytotoxic response directed against cells bearing these antigens, and thus in parenchymal damage of the graft tissue [14-20] In previous studies [21-25], we and other showed that graft-infiltrating lymphocytes can be cultured from cardıac graft tissue specimens During acute rejection episodes, a higher proportion of these biopsies yielded lymphocyte cultures, of which the majority was cytotoxic against donor-derived cells

The influence of HLA mismatches between donor and recipient on phenotypes and effector function of graft infiltrating cells has never been systematically studied Therefore we analyzed the effect of HLA-A, $-B$, and -DR mismatches on the functional and phenotypic characteristics of these cells in a large serres of endomyocardial biopsies (EMBs) from 118 heart transplant recipients Moreover, we investigated the immunogenicity of individual mismatched HLA antigens

\section{MATERIALS AND METHODS}

\section{Patients}

We studied EMB-derived graft-1nfiltrating cells from 118 heart transplant recipients who underwent transplantations between February 1988 and January 1990 All patients had received preoperative blood transfusions and all received cyclosporine and low-dose prednisone as maintenance immunosuppression The actuarial patient survival was $89 \%$ at 4 years The mean number of mis- matches between donor and recipient was 125,162 , and 140 for HLA-A, -B, and -DR, respectively Table 1 shows the distribution of the patients among the different matched groups HLA histocompatibility was based on matching for broad specificities Homozygosities were considered as one mismatched antigen

Rejection was monitored by EMB Grading of the biopsies was according to Billınghams [26] criteria of none, mild, moderate, and severe rejection For the $\mathrm{d}_{1}$ agnosis of moderate rejection, the coexistence of myocyte necrosis and mononuclear infiltrates was required In that case, antirejection treatment was instituted, which consisted of bolus sterords or, in case of ongoing rejection, of a 2-week course of a polyclonal rabbit ant1thymocyte-globulin preparation There were no cases of severe rejection In the early posttransplant period, serial biopsy specimens were obtained at weekly intervals Later, EMBs were taken less frequently, declınıng to once very 4 months at 1 year After an acute rejection episode, the next biopsy sample was taken 1 week following rejection therapy Three patients who died withın 3 weeks after transplantation (from other causes than severe rejection) were excluded from this study We received a total of $1285 \mathrm{EMBs}, 4-22$ from each patient (medıan, 10)

\section{HLA Typing}

Spleen cells or peripheral blood mononuclear cells (obtained by Ficoll separation of heparinized blood) were typed for HLA class I antigens according to the standard National Institutes of Health lymphocytotoxicity assay, and typed for HLA-DR by the two-color fluorescence assay with a set of highly selected antisera [27]

\section{Culture Method}

Lymphocyte cultures These were establıshed from EMBs as described previously [21] In brief, each biopsy specimen was divided into two or more fragments and placed into two or more wells of a 96-well round-bottom tissue culture plate (Costar 3799, Cambridge, MA, USA) with $200-\mu$ I culture medium in the presence of $10^{5}$ irradiated ( $40 \mathrm{~Gy}$ ) autologous perıpheral blood mononuclear cells as

TABLE 1 Distribution of the 118 patients among the different mismatched groups

\begin{tabular}{lccc}
\hline & \multicolumn{3}{c}{ Number of patients } \\
\cline { 2 - 4 } HLA & $0 \mathrm{MM}^{a}$ & $1 \mathrm{MM}$ & $2 \mathrm{MM}$ \\
\hline A & 11 & 67 & 40 \\
B & 4 & 40 & 74 \\
DR & 9 & 53 & 56 \\
\hline
\end{tabular}

MM, mismatch 
feeders Culture medium consisted of RPMI-1640Dutch modification (Gibco, Paisley, Scotland) supplemented with $10 \%$ vol/vol lectin-free Lymphocult-T-LF (Biotest, Dreietch, Germany) as exogenous source of IL2 , $10 \%$ pooled human serum, $4 \mathrm{mM}$ L-glutamine, 100 $\mathrm{IU} / \mathrm{ml}$ penicillın, and $100 \mu \mathrm{g} / \mathrm{ml}$ streptomycin When growth was observed, the contents of several wells of a culture were pooled and transferred to more wells when sufficient cell density was reached $\left(10^{5}-10^{6}\right.$ cells $\left./ \mathrm{ml}\right)$ When growth was slowing down or cell death was observed, the cultures were restımulated by addıng either $10^{5}$ irradiated ( $40 \mathrm{~Gy}$ ) donor spleen cells/well or $5 \times 10^{3}$ Epstein-Barr virus (EBV)-transformed donor cells/well (irradiated with $80 \mathrm{~Gy}$ ) Only $6 \%$ of the cultures needed restimulation in order to obtain sufficient amounts of cells for a cell-mediated cytotoxicity assay

Allogeneic stzmulatorltarget cells Phytohemagglutının (PHA) blasts were obtained by culturing spleen cells for at least 5 days in the presence of $1 \%$ PHA-M (Difco, Detroit, MI, USA) and culture medium RPMI 1640 $+5 \%$ pooled human serum and $5 \%$ lymphocult- $T$ (Biotest) EBV-transformed B-cell lines were set up and cultured as previously described [28]

\section{Phenotypic Analysis}

The phenotypes of the graft-infiltrating lymphocytes were analyzed by two-color flow cytometry after staining with monoclonal antibodies directed against CD8 (ant1leu2) and CD4 (ant1-leu3), both purchased from Becton Dickinson (Mountain View, CA, USA) The antibodies were directly conjugated to fluorescein or phycoerythrin A more extensive phenotypic characterization of the cultured cells is described elsewhere [21] A T-cell subset was considered to be predominant when it comprised more than $60 \%$ of the cells in a culture

\section{Cell-Mediated Cytotoxicity Assays}

Biopsy-derived bulk cultures were tested for donordirected cytotoxicity in a standard 4-hour ${ }^{51} \mathrm{Cr}$-release assay according to the European Standard Technique [29] As target cells we used donor-derived cell lines and a panel of unrelated target cells (PHA T-cell blasts or EBV-transformed B-cell lines) sharing one or more HLA antigens with the donor, and a third-party control The specificity for donor HLA class I (HLA-A and -B) or class II (HLA-DR) antigens was determined by testing the cytotoxicity of the bropsy-derived T-cell lines against a panel consisting of 5-10 (median, 7) target cell lines Each individual HLA antigen was represented $1-4$ times in the cell panels If the cytotoxicity against an HLA antigen was difficult to interpret, such as the example of HLA-B 15 in Fig 1 (left panel), this antigen was con- sidered to be not tested The HLA antigens studied in the present report are listed in Table 2

${ }^{51} \mathrm{Cr}$-labeled target cells, $25 \times 10^{3}$, were mixed with effector cells in $200 \mu \mathrm{l}$ culture medium per well in 96well U-bottom microtiter plates (Costar) Serial double dilutions with effector-target ratios varying from 1251 up to 801 were used The plates were incubated for 4 hours at $37^{\circ} \mathrm{C}$ in $5 \% \mathrm{CO}_{2}$ Supernatants were harvested with a Skatron harvesting system (Skatron-AS, Norway) and the release of ${ }^{51} \mathrm{Cr}$ was assayed in a Packard gammacounter (Packard Instruments, Downers Grove, USA) According to the recommendations of the European CML Workshop [29], cultures were considered cytolytic when the experimental lysis percentage exceeded $10 \%$ at an effector-target ratio of 201 or greater, and the slope of a graph was positive Some representative cytotoxicity titrations are represented in Fig 1 Series of doubledilution studies revealed that lysis percentages of autologous control cell lines did not exceed $10 \%$

\section{Statistical Analysis}

The significance of differences among the various groups of patients and cultures was analyzed by Mann-Whitney test or by chi-squared test, respectively Freedom from rejection rates were computed by actuarial methods and statistical significance was estımated by log-rank analysis

\section{RESULTS}

HLA mismatibes and acute refection In the DR-matched patient group $56 \%$ of patients remained free from rejection at 6 months, compared with $29 \%$ of patients with one and $22 \%$ with two DR mismatches with their donors For the combination of HLA-B and -DR antigens a significant effect on freedom of rejection was observed $\left(p<005, F_{1 g} 2\right)$ Transplants with two or fewer mismatched HLA-B and -DR antigens displayed a $14 \%$ higher freedom from rejection at 6 months compared with those with three or four HLA-B and -DR incompatibilities The number of HLA-A mismatches did not show any additive effect on freedom from rejection rates

No significant relation between the number of acute rejection episodes and the number of mismatches on the individual $\mathrm{A}, \mathrm{B}$, or DR locus was observed

HLA masmatches and CD $4 / C D 8$ phenotypes From all patients, approximately $60 \%$ of the EMBs yielded lymphocyte cultures The success of culturing did not depend on the degree of HLA-DR matching between donor and recipient, since the mean percentages growing biopsy specimens were highly comparable in patients with zero, one, or two DR mismatches with their donors $(57 \%$, 


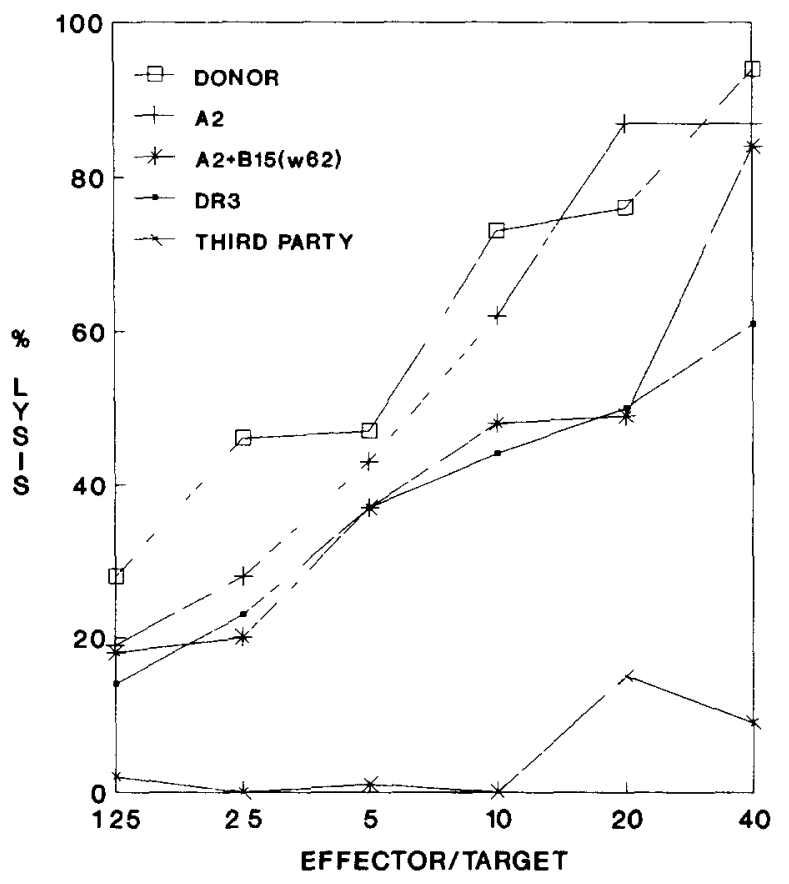

FIGURE 1 Representative example of a positive (left) and a negative cytotoxicity titration (right) of biopsy-derived cultures from two different patients The cultures were not restimulated with donor cells and were cultured for 40 and 26 days, respectively In these examples, EBV-transformed B-cell lines were used as targets The HLA antigens shared by target cells and the heart donor are indicated HLA typing (left) recipient $A 1, A 10(25), B 18, B 35, D R 2(w 15)$, and DRw6(w 13), and donor A2, B 15(w62), B18, DR2(w15), and DR3, and (right) recipient A2, A3, B35, B37, DR7, and DRw 10, and donor A 10(26), A 19(29), B 12(44), B22(55), DR 5(11), and DR7

$59 \%$, and $63 \%$, respectively) In the first 180 days after transplantation, the number of HLA-DR mismatches between donor and recipient had a pronounced influence on the phenotypic composition of the EMB-derived lymphocyte cultures ( $F_{1} g$ 3) Recipients with HLA-A and -B mismatches but without DR mismatches with their donors yielded cultures that were dominated by $\mathrm{CD} 8^{+} \mathrm{T}$ cells in $60 \%$ of cases $(p<0005$ compared with DRmismatched combinations) In cultures from patients with DR mismatches, $\mathrm{CD}^{+}{ }^{+} \mathrm{T}$ cells comprised the predominant T-cell subset The predominance of $\mathrm{CD}^{+}{ }^{+} \mathrm{T}$ cells was most evident in patients with two DR mismatches with their donors $(p=0025$ compared with DR-matched combinations) After the first 6 posttransplant months, no significant differences between the groups were found

The influence of the degree of HLA class I matching on growth and phenotypic composition of the cultures was hard to evaluate, because all patients except one had one or more class I mismatches The EMB-derived cultures $(n=7)$ from this single patient were all dominated by $\mathrm{CD}^{+} \mathrm{T}$ cells In the remaining patients, no signif-

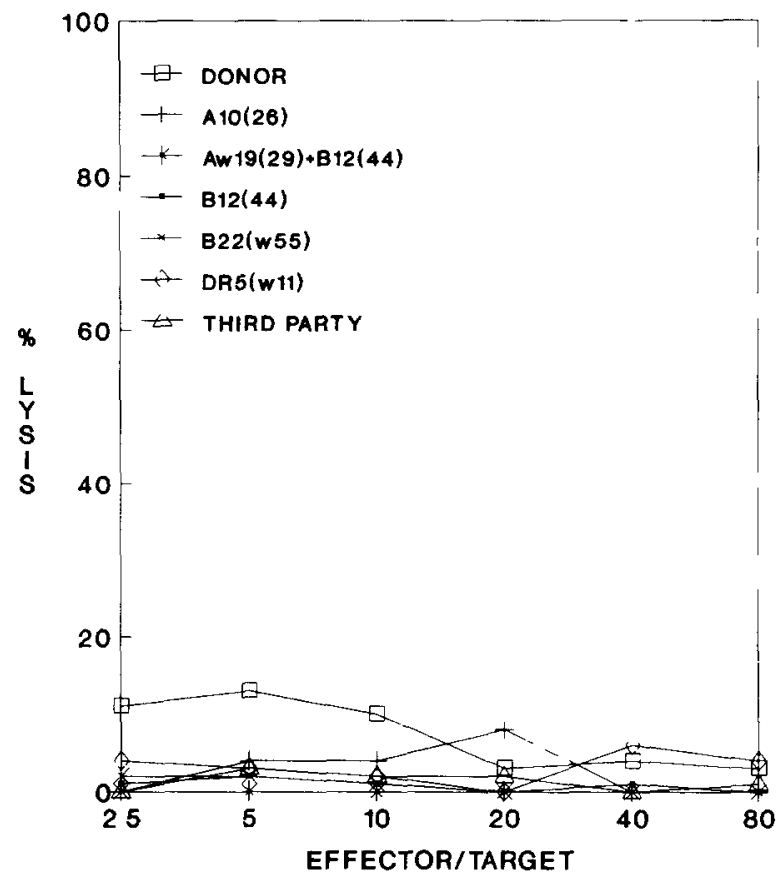

icant relation was found between the number of HLA class I mismatches and the degree of CD8 predominance

Cytotoxictty In vitro studies showed that the majority ( $n$ $=234$ or $75 \%$ ) of the tested EMB-derived T-lymphocyte cultures $(n=324)$ was cytotoxic against donor antigens Of these cultures, $165(53 \%)$ and $154(49 \%)$ were cytotoxic against HLA-B and -DR antigens, respectively Significantly fewer cultures $(n=107,36 \%, p<$ 0 005) showed cytotoxicity against HLA-A antigens This higher immunogenicity of HLA-B and -DR ant1gens was also apparent when we analyzed the CTL reactivity against several individual HLA antigens (Table 2) This was analyzed for broad specificities and not splits Against most HLA-A antigens a low percentage of reactive cultures was found Only HLA-A2 was found to be of comparable immunogenicity to HLA-B and -DR antigens $O f$ the 90 tested cultures from 23 donorrecipient combinations with an HLA-A2 incompatibility, $62 \%$ showed reactivity against $A 2$, which was significantly higher than generally found against other HLA-A antigens ( $p<0001$, Table 2$)$ When analyzed as the percentage reactive cultures for each individual patient, a median of $60 \%$ HLA-A2-reactive cultures was found, which was again significantly higher than against other mismatched HLA-A antigens ( $\left.p<0001, F_{1 g} 4\right)$ Among the HLA-B antigens, no evidence for such an immunodominant locus allele was found Generally, a high percentage of tested cultures showed cytotoxicity against mismatched HLA-B antigens, while against some of these antigens the reactivity was lower (Tables 2 and 3) A similar pattern was found for reactivity agatnst HLA-DR mismatches (Table 3) 
TABLE 2 CML reactivity of EMB-derived lymphocyte cultures against the most prevaling mismatched HLA antigens, expressed as numbers and percentages of cultures reactive against an HLA antigen

\begin{tabular}{|c|c|c|c|}
\hline \multirow[b]{2}{*}{ HLA MM ${ }^{a}$} & \multicolumn{2}{|c|}{ Number of cultures } & \multirow[b]{2}{*}{$\begin{array}{c}\text { No of } \\
\text { patients tested }\end{array}$} \\
\hline & Tested & $\begin{array}{l}\text { Positive in } \\
\text { CML }(\%)\end{array}$ & \\
\hline \multicolumn{4}{|l|}{ HLA-A } \\
\hline A 1 & 73 & $18(25)$ & 24 \\
\hline $\mathrm{A} 2$ & 90 & $56(62)$ & 23 \\
\hline A3 & 58 & $19(33)$ & 22 \\
\hline A 10 & 38 & $7(18)$ & 12 \\
\hline A 11 & 36 & $7(19)$ & 7 \\
\hline Aw 19 & 119 & $32(27)$ & 29 \\
\hline \multicolumn{4}{|l|}{ HLA-B } \\
\hline B5 & 58 & $23(40)$ & 11 \\
\hline B7 & 46 & $21(46)$ & 19 \\
\hline $\mathrm{B} 8$ & 54 & $23(43)$ & 14 \\
\hline $\mathrm{B} 12$ & 68 & $38(56)$ & 19 \\
\hline B 18 & 34 & $13(38)$ & 11 \\
\hline $\mathrm{B} 27$ & 21 & $11(52)$ & 7 \\
\hline B35 & 59 & $32(54)$ & 15 \\
\hline B 40 & 37 & $9(24)$ & 15 \\
\hline B 15 & 30 & $4(13)$ & 9 \\
\hline \multicolumn{4}{|l|}{ HLA-DR } \\
\hline DR 1 & 85 & $35(41)$ & 20 \\
\hline DR2 & 42 & $17(40)$ & 16 \\
\hline DR3 & 62 & $31(50)$ & 19 \\
\hline DR4 & 72 & $33(46)$ & 17 \\
\hline DR5 & 87 & $32(37)$ & 18 \\
\hline DRw6 & 50 & $22(44)$ & 12 \\
\hline DR7 & 59 & $29(49)$ & 16 \\
\hline DRw8 & 37 & $10(27)$ & 10 \\
\hline
\end{tabular}

MM, mismatch

In time, donor-directed cytotoxicity declined significantly ( $p<003$ ), from 79\% (181 of 229) of the cultures established from EMB taken in the first 180 days to $61 \%$ ( 58 of 95) after 6 months This was due to a fall in the percentage of cultures that were cytotoxic against mismatched donor HLA-B and -DR antigens (Table 4)

$A$ higher number of HLA-A, -B, or -DR mismatches between donor and recipient was found to be positively correlated with the percentage of cytotoxic cultures directed against these antigens (Table 5) Biopsy samples from patients with two A,B, or DR mismatches with their donors yielded a higher proportion of cytotoxic cultures directed against these antigens when compared with EMB from patients who had only one mismatch for any of these HLA antigens The pronounced dose effect of HLA-A mismatches was mainly found when the second HLA-A antigen was A2 (in $62 \%$ of cultures from donor-recipient combinations with two HLA-A mismatches and a positive CML against HLA-A, compared

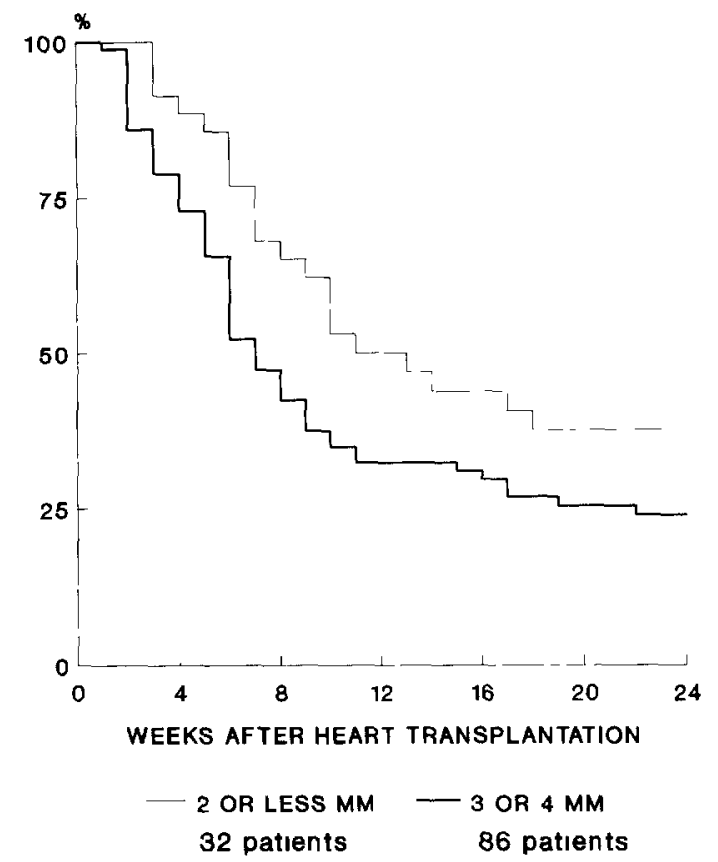

FIGURE 2 Actuarial freedom from rejection of heart transplants in relation to matching for HLA-B and -DR antigens The freedom from rejection of patients with $\leqslant 2$ or $>3$ mismatches for the combined B and DR antigens were $65 \%$ and $42 \%$ at 2 months $(p=001)$, and $37 \%$ and $24 \%$ at 6 months $(p=005)$, respectively

with only $28 \%$ of cultures not reactive against HLA-A, $p<0001, \chi^{2}$ test)

\section{DISCUSSION}

The present study shows that the number of mismatched HLA-B and -DR antigens on a transplanted heart, but also HLA-A antigens, is positively correlated with the percentage of cytotoxic EMB-derived cultures directed against these mismatched HLA antigens The incidence of HLA-A-directed cytotoxicity was lower, however, than that directed against B or DR mismatches This apparently high immunogenicity of HLA-B and -DR antigens may account for the significantly lower freedom from rejection rates in the patient group with more than two HLA-B and -DR mismatches This association between the number of HLA-B and -DR mismatches and freedom from rejection has also been described by others [13] Studies on the effect of matching for HLA antigens in renal [3-8] and heart transplantation $[10,11]$ showed that matching for HLA-B and -DR has a significant influence on graft survival In normal individuals HLA-B antigens are more immunogenic to cytotoxic $T$ cells than HLA-A antigens, although major individual differences were found in the frequency of alloreactive CTL precursor (CTLP) directed against HLA class I [3033 ] and class II [34] antigens Until now, a direct cor- 
$<180$ DAYS

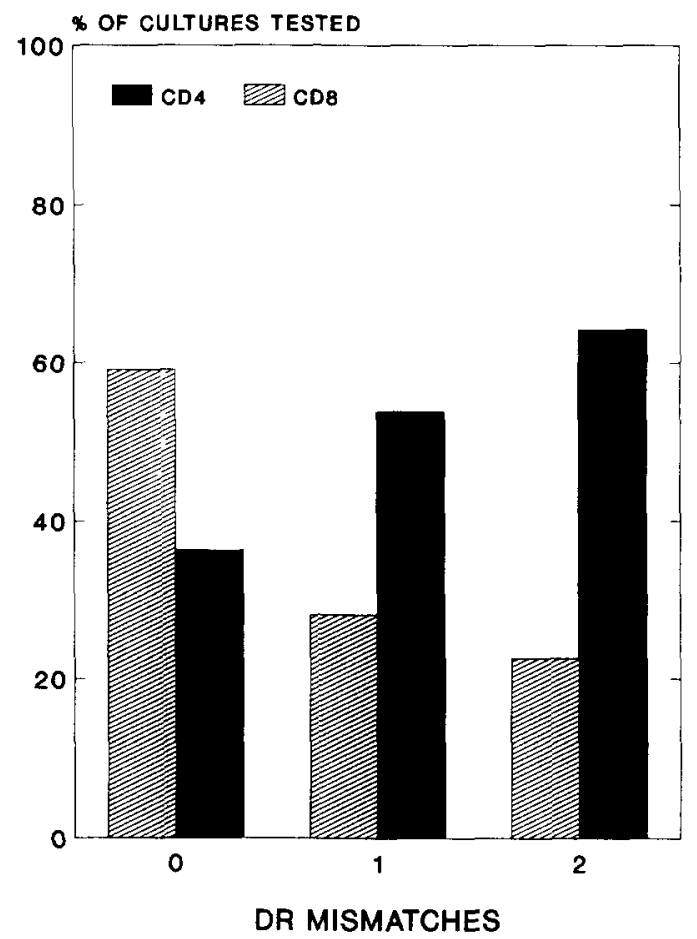

FIGURE 3 Predomınant phenotype of EMB-derıved lymphocyte cultures in relation to the number of HLA-DR mismatches (MM) between donor and recipient In the first 180 days after transplantation, cultures from patients without DR mismatches with their donors were most often dominated by $\mathrm{CD}^{+}$cells $(p<0005$ compared with DR-matched combinations), while in cultures from patients with DR mismatches $\mathrm{CD}^{+}{ }^{+} \mathrm{T}$ cells comprised the predominant subset in the majority of cultures (left) After the first 6 postransplant months, no significant differences between the groups were found (right) Numbers of cultures tested (left) 0 DR MM ( $n$ $=22), 1 \mathrm{DR} \operatorname{MM}(n=160)$, and $2 \mathrm{DR} \mathrm{MM}(n=226)$, and (right) $0 \mathrm{DR} \mathrm{MM}(n=17), 1 \mathrm{DR} \mathrm{MM}(n=106)$, and $2 \mathrm{DR}$ $\mathrm{MM}(n=110)$

relation between pretransplant CTLp frequencies and transplant outcome has not been shown But it was found in mice that an increase of CTLp frequency after transplantation is associated with allograft rejection [35] In renal transplant patients, a decrease of donorspecific CTLp is correlated with good graft function [36], and a low patient-specific CTLp frequency in a bone marrow donor gives less graft-versus-host disease [37]

In the present study, a "dose-effect" phenomenon of the number of mismatches on CML reactivity was found for HLA-A, -B, and -DR antigens This dose-effect phenomenon of HLA mismatches could also be observed in the higher 6-month freedom from rejection in patients with two or fewer HLA-B and -DR mismatches in the
>180 DAYS

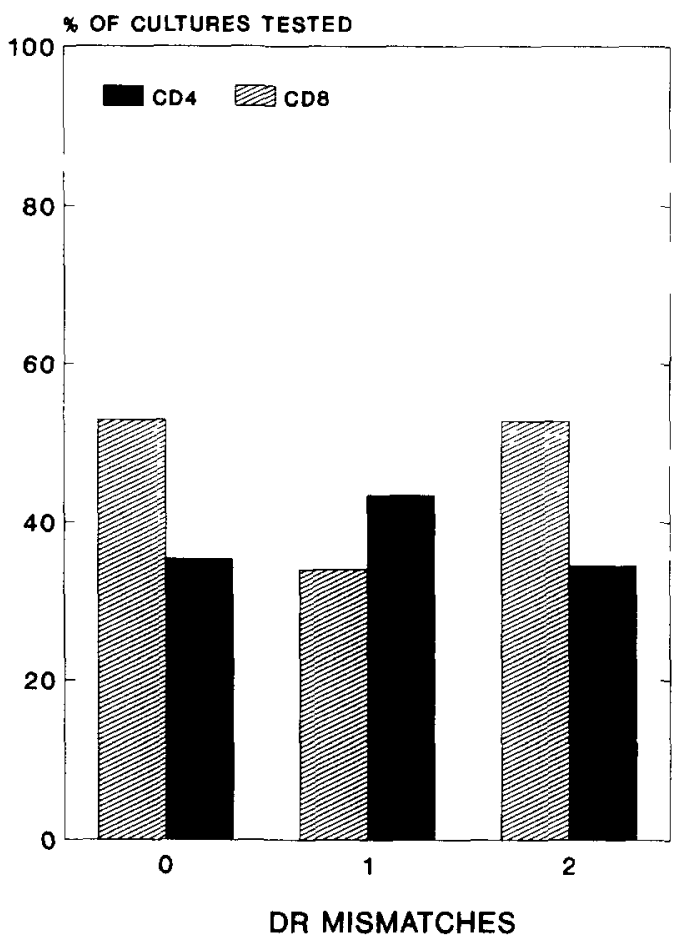

first half year This is consistent with data of Opelz [3, 10,38 , who showed that during the early posttransplant course, HLA-B and -DR mismatches exerted a strong influence on transplant survival, in contrast to mismatched HLA-A antigens However, the influence of the latter on long-term survival was comparable to that of HLA-B and -DR antigens [38] Interestingly, the dose effect for HLA-A mismatches was manly found when the second mismatched antigen on the A locus was A2

Our finding of high reactivity against HLA-A2 ant1gens expressed on donor cells confirms the observation of others [33] (Roelen, personal communication) that HLA-A2 is an immunodominant locus allele They found high ant1-A2 CTLP frequencies among normal individuals and in highly sensitized patients awaitıng renal transplantation, respectively By inhibition experiments with CD8 monoclonal antibodies, it was shown that all ant1-HLA-A (including A2) CTLps could be inhibited, indicating that these cytotoxic $T$ cells have a low avidity for HLA-A antigens Of HLA-B-directed CTLs, significantly fewer could be inhibited In previous reports $[39,40]$, we have shown that low-avidity alloreactive CTLs are probably not relevant for the rejection process High-avidity alloreactive CTLs can be demonstrated in the peripheral blood of highly sensitized candidates for renal (re)transplantation, and in the grafts of rejecting heart transplant recipients Interestingly, preliminary data from Eurotransplant (Thorogood) show 


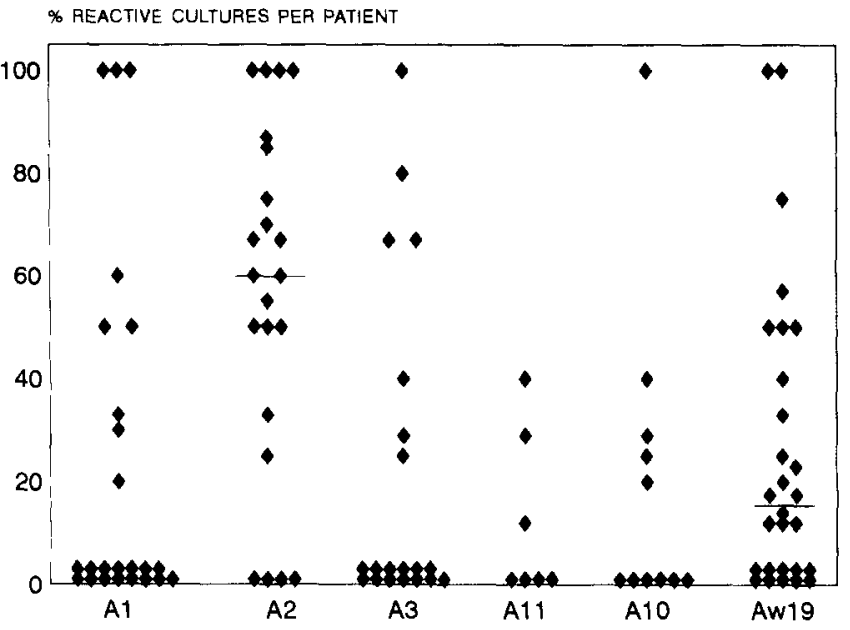

FIGURE 4 Percentage cytotoxic cultures against individual mismatched HLA-A antigens Each dot represents one patient From each patient, 1-12 (median, 4) biopsy-derived cultures could be tested Against an HLA-A2 mismatch, a significantly higher percentage of reactive cultures was found when compared with other mismatched HLA-A antigens $(p<0001$, Mann-Whitney test) Medians of a group are indicated as borizontal lines

TABLE 3 CML reactivity against mismatched HLA-B and -DR antigens, expressed as median percentage reactive cultures per patient group with this HLA incompatibility

Median percentage
reactive cultures

\begin{tabular}{lr}
\hline HLA-B & \\
B5 & 22 \\
B7 & 50 \\
B8 & 38 \\
B12 & 60 \\
B18 & 60 \\
B27 & 50 \\
B35 & 60 \\
B40 & 0 \\
B15 & 0 \\
HLA-DR & \\
DR 1 & 45 \\
DR2 & 23 \\
DR3 & 40 \\
DR4 & 67 \\
DR5 & 33 \\
DRw6 & 22 \\
DR7 & 40 \\
DRw8 & 6 \\
\hline
\end{tabular}

From each patient, 1-12 (median, 4) biopsyderived cultures could be tested
TABLE 4 CML specificity of EMB-derived cultures against panel cells sharing mismatched HLA-A, -B, or -DR antigens with the donor relation with time after transplantation

\begin{tabular}{lccc}
\hline & \multicolumn{3}{c}{ Number of reactive cultures } \\
\cline { 2 - 4 } CML specificity & $\begin{array}{c}<180 \text { days } \\
n(\%)^{q}\end{array}$ & $\begin{array}{c}>180 \text { days } \\
n(\%)\end{array}$ & $p^{b}$ \\
\hline HLA-A & $79(38)$ & $28(33)$ & NS \\
HLA-B & $127(57)$ & $38(40)$ & $<001$ \\
HLA-DR & $120(55)$ & $34(37)$ & $<001$ \\
\hline
\end{tabular}

In the first half-year, the incidence of HLA-A-directed cytotoxicity was significantly lower than that aganst B or DR antigens $(\phi<0$ 001)

${ }^{*}$ Number and percent of reactive cultures

${ }^{b} \chi^{2}$ test

that a mismatch for HLA-A2 does not result in a lower kidney transplant survival In the present study, this could not be evaluated, because all patients also had several HLA-B and -DR mismatches with their donors

In the one and two DR-mismatched groups, significantly more CD4-dominated cultures were derived from the biopsies than in the DR-matched group $\mathrm{CD}^{+}$cells are known to be of crucial importance in the initiation of rejection [14-20] Interaction of these cells with donor class II MHC antigens expressed on the graft tissue and on passenger leukocytes of donor origin results in act1vation of $\mathrm{CD}^{+}$cells that recognize MHC class I ant1gens Both $\mathrm{CD} 4^{+}$and $\mathrm{CD} 8^{+}$cells play a role in the rejection of mismatched grafts [14-16] Rejection of class I disparate grafts appears to depend most on $\mathrm{CD} 8^{+}$ cells, although $\mathrm{CD} 4^{+}$cells can be activated as well via presentation of donor MHC class I antigens on recipient antigen-presenting cells in the context of self-HLA class II molecules [41, 42]

More than 180 days after transplantation, the decline found in the number of the CD4-dominated cultures may be due to a lower expression of donor-type class II antigens on graft tissue, due to the replacement of donor dendritic cells by the patients' antigen-presenting cells $[43,44]$ As a consequence, fewer class-II-specific $\mathrm{CD}^{+}$lymphocytes may be attracted to the graft Data from animal heart transplant models show that this reduction of the number of HLA class-II-expressing dendritic cells may already start early after transplantation, which may explain our finding that in some patients an earlier decline of DR-directed cytotoxicity is found [45] (data not shown)

Lower expression of donor-type HLA antigens on graft tissue may also play a role in the lower incidence of cytotoxicity directed against these antigens after 6 
TABLE 5 The dose effect of the number of HLA mismatches per locus on CML reactivity of EMB-derived cultures

\begin{tabular}{llll}
\hline & \multicolumn{3}{c}{ Number of reactive cultures } \\
\cline { 2 - 4 } CML specificity & $\begin{array}{l}1 \mathrm{MM}^{a} \\
n(\%)^{b}\end{array}$ & $\begin{array}{l}2 \mathrm{MM} \\
n(\%)\end{array}$ & $p^{c}$ \\
\hline HLA-A & $86(34)$ & $77(52)$ & 0005 \\
HLA-B & $78(50)$ & $145(60)$ & 0055 \\
HLA-DR & $73(40)$ & $119(52)$ & 0025 \\
\hline
\end{tabular}

${ }^{a}$ MM, mismatch

${ }^{b}$ Number and percent of reactive cultures

$\chi^{2}$ test

months $[47,48]$ Next to the influence of HLA expression on the graft, other mechanisms may also be involved Specific suppression of antidonor responses by regulatory $T$ cells, clonal anergy or deletion of antidonor $T$ cells, or downmodulation by anti1diotypic antibodies are thought to be important mechanisms contributing to acquired immune tolerance in human transplant recipients $[21,36,48-50]$

In conclusion, we showed that the number and nature of HLA mismatches between donor and recipient strongly influence the cellular immune response withın the transplanted heart, resulting in a significant effect on freedom from rejection

\section{REFERENCES}

1 Dausset J, Hors J, Busson M, Festenstein H, Bact CBD, Path MRC, Olıver RTD, Chır B, Parıs AMI, Sachs JA Serologically defined HL-A antigens and long-term survival of cadaver kidney transplants a joint analysis of 918 cases performed by France transplant and the London transplant group N Engl J Med 290 979, 1974

2 van Rood JJ Leucocyte grouping a method and its application Thesis, University of Leiden, Leiden, The Netherlands, 1962

3 Opelz G Effect of HLA matching in 10,000 cyclosporine-treated cadaver kidney transplants Transplant Proc 19641,1987

4 Thorogood J, Persijn GG, Schreuder GMTh, D'Amaro J, Zantvoort FA, van Houwelingen JC, van Rood JJ The effect of HLA matching on kidney graft survival in separate posttransplantation intervals Transplantation 50 146,1990

5 Gilks WR, Gore SM, Bradley BA Renal transplant rejection transient immunodominance of HLA mismatches Transplantation 50141,1990

6 Hendriks GFJ, van Steenberge EPM, Schreuder GMTh, Wenting GJ, Mochtar B, Bos E, Simoons ML, Balk AHMM, Laird-Meeter K, Essed CE, Baumgartner D,
Jeekel J, Weimar W Treatment with cyclosporin and risks of graft rejection in male kidney and heart transplant recipients with non-O blood BMJ 297888,1988

7 Takıff $H$, Cook DJ, Hımaya NS, Mickey MR, Terasakı PI Dominant effect of histocompatibility and ten year kıdney transplant survival Transplantation 45410 , 1988

8 Terasakı PI (ed) Clınıcal Transplants 1989, vol 3 Los Angeles, UCLA Tissue Typing Laboratory, 1989

9 Busson M, Gony J, Hors J Is the strength of single HLA antigen mismatch varıable in kidney transplant survival? Transplantation 28 313, 1979

10 Opelz G Effect of HLA matching in heart transplantation Transplant Proc 21 794, 1989

11 Khaganı A, Yacoub M, McCloskey D, Awad J, Burden M, Fitzgerald M, Hawes R, Holmes J, Smith J, Banner $\mathrm{N}$, Festenstein $\mathrm{H}$ The influence of HLA matching, donor/recipient sex, and incidence of acute rejection on survival in cardiac allograft recipients receiving cyclosporin A and azathoprıne Transplant Proc 21799,1989

12 DiSesa VJ, Kuo PC, Horvath KA, Mudge GH, Collıns JJ, Cohn LH HLA histocompatibility affects cardtac transplant rejection and may provide one basis for organ allocation Ann Thorac Surg 49 220, 1990

13 Laufer G, Miholic J, Laczkovics A, Wollenek G, Holzinger C, Hajek-Rosenmerer A, Wuzl G, Schreiner W, Buxbaum $P$, Wolner $E$ Independent risk factors predicting acute graft rejection in cardiac transplant recipients treated by triple drug immunosuppression $\mathrm{J}$ Thorac Cardiovasc Surg 981113,1989

14 Lowry RP, Forbes RDC, Blackburn J, Marghesco D The pivotal role of cytotoxic $T$ cells in the rejection of heart grafts bearing isolated class I disparities Transplant Proc 27227,1985

15 Lowry RP, Gurley KE, Clarke Forbes RD Immune mechanısms in organ allograft rejection I Delayed-type hypersensitivity and lymphocytotoxicity in heart graft rejection Transplantation 36391,1983

16 Lowry RP, Gurley KE Immune mechanisms in organ allograft rejection III Cellular and humoral immunity in rejection of organ allografts transplanted across MHC subregion disparity RT1 B (RT1 D) Transplantation 35 405, 1983

17 Strom TB The cellular and molecular basis of allograft rejection what do we know' Transplant Proc 20143 , 1988

18 Bach FH, Sachs DH Transplantation Immunology N Engl J Med 317 489, 1987

19 Hayry P Mechanisms of rejection Curr Opın Immunol 11230,1989

20 Hall BM Transplantation tolerance a 1988 perspective Transplant Proc 21 816, 1989

21 Ouwehand AJ, Vaessen LMB, Baan CC, Jutte NHPM, Balk AHMM, Essed CE, Bos E, Claas FHJ, Wermar W Alloreactive lymphord infiltrates in human heart transplants loss of class II directed cytotoxicity more than 
three months after transplantation Hum Immunol 30 50,1991

22 Zeevı A, Fung JJ, Zerbe TR, Kaufman C, Rabin BS, Griffith BP, Hardesty RL, Duquesnoy RJ Allospecificity of activated $\mathrm{T}$ cells grown from endomyocardial biopsies from heart transplant patients Transplantation 41620 , 1986

23 Mayer TG, Fuller AA, Fuller TC, Lazarovits AI, Boyle LA, Kurnick JT Characterization of in vivo-activated allospecific $T$ lymphocytes propagated from human renal allograft biopsies undergoing rejection $\mathrm{J}$ Immunol 134258,1985

24 Carlquist JF, Hammond EH, Anderson JL Propagation and characterization of lymphocytes from rejecting human cardiac allografts J Heart Transplant 7 397, 1988

25 Moreau JF, Bonneville M, Peyrat MA, Godard A, Jacues Y, Desgranges C, Soulillou JP T lymphocyte cloning from rejected human kidney allografts $\mathrm{J}$ Clin Invest 78 874,1986

26 Billingham ME Diagnosis of cardiac rejection by endomyocardial biopsy J Heart Transplant 125, 1982

27 van Rood JJ, van Leeuwen A, Ploem JS Simultaneous detection of two cell populations by two-colour fluorescence and application to the recognition of B-cell determinants Nature 262795,1976

28 Miller G, Shope T, Lisco H, Stitt D, Lipman M Epstein-Barr virus transformation cytopathic changes in squirrel monkeys and marmoset leucocytes Proc Natl Acad Scı USA 69 383, 1972

29 European CML Working Group Human histocompatibility testing by $\mathrm{T}$ cell mediated lympholysis a European CML Standard technique-report from the European CML Workshop Tissue Antigens 16 335, 1980

30 Breur-Vriesendorp BS, Vingerhoed J, Schaasberg WP, Ivanyi $\mathrm{P}$ Variations in the $\mathrm{T}$-cell repertoire against HLA antigens in humans Hum Immunol 27 1, 1990

31 Sharrock EM, Man S, Wanachiwanawin W, Batchelor JR Analysis of the alloreactive $T$ cell repertoure in man I Differences in precursor frequency for cytoxic cell responses against allogeneic MHC molecules in unrelated individuals Transplantation 43699,1987

32 Zhang L, Guang S, Vandekerckhove B, Termıtelen A, van Rood JJ, Claas FHJ Analysis of cytotoxic $T$ cell precursor frequencies directed against individual HLA-A and -B alloantigens J Immunol Methods 121 39, 1989

33 Breur-Vriesendorp BS, Vingerhoed J, van Twuyver E, de Waal LP, Ivanyi P Frequency analysis of HLA-specific cytotoxic $T$ lymphocyte precursors in humans Transplantation 51 1096, 1991

34 Man S, Lechler RI, Batchelor JR, Sharrock CEM Individual variation in the frequency of HLA class II-specific cytotoxic T lymphocyte precursors Eur J Immunol 20 847,1990 mechanısms of alloreactivity I Frequency of donorreactive $\mathrm{T}$ lymphocytes in sponge matrix allografts Transplantation 4175, 1986

36 Herzog WR, Zanker B, Irschıck E, Huber C, Franz HE, Wagner $H$, Kabelitz $D$ Selective reduction of donorspecific $\mathrm{T}$ lymphocyte precursors in patients with a wellfunctioning kidney allograft Transplantation 43384 , 1987

37 Kamınskı E, Hows J, Man S, Brookes P, Mackınnon S, Hughes T, Avakian O, Goldman JM, Batchelor JR Prediction of graft versus host disease by frequency analysis of cytotoxic T cells after unrelated donor bone marrow transplantation Transplantation 48608,1989

38 Opelz G Strength of HLA-A, HLA-B and HLA-DR mismatches in relation to short- and longterm kidney graft survival Transplant Int 5(Suppl 1) S621, 1992

39 Roelen D, Datema G, van Bree S, Zhang L, van Rood J, Claas F Evidence that antibody formation against a certain HLA alloantigen is associated not with a quantitative but with a qualitative change in the cytotoxic $T$ cells recognizing the same antigen Transplantation 53899 , 1992

40 Ouwehand AJ, Baan CC, Roelen DL, Vaessen LMB, Balk AHMM, Jutte NHPM, Bos E, Claas FHJ, Weımar W The detection of cytotoxic $T$ cells with high affinity receptors for donor antigens in the transplanted heart as prognostic factor for graft rejection Transplantation 561223,1993

41 Liu Z, Braunstein NS, Suciu-Foca N T cell recognition of allopeptides in context of syngenerc MHC J Immunol 148 35, 1992

42 Benıchou G, Takızawa PA, Olson CA, McMillan M, Sercarz EE Donor major histocompatibility complex (MHC) peptides are presented by recipient MHC molecules dur1ng graft rejection J Exp Med 175 305, 1992

43 Steinhoff G, Wonigeit K, Schafers HJ, Haverich A Sequentral analysis of monomorphic and polymorphic major histocompatibility complex antigen expression in human heart allograft biopsy specimens J Heart Transplant 5 360,1989

44 Suitters A, Rose M, Higgins A, Yacoub MH MHC antigen expression in sequential biopsies from cardiac transplant patients correlation with rejection Clin Exp Immunol 69575,1987

45 Larsen CP, Morris PF, Austyn JM Migration of dendritic leukocytes from cardiac allografts into host spleens a novel pathway for initiation of rejection J Exp Med 171 307,1990

46 Suitters A, Rose M, Higgins A, Yacoub MH MHC antigen expression in sequential biopsies from cardiac transplant patients correlation with rejection Clin Exp Immunol 69575,1987

47 Bishop GA, Waugh JA, Hall BM Expression of HLA 
antigens on renal tubular cells in culture II Effect of increased HLA antigen expression on tubular cell stimulation of lymphocyte activation and on their vulnerability to cell-mediated lysis Transplantation 46303,1988

48 Vandekerckhove BAE, Datema G, Koning F, Goulmy E, Persıjn GG, van Rood JJ. Claas FHJ, de Vrıes JE Analysis of the donor-specific cytotoxic $T$ lymphocyte repertorre in a patient with a long term surviving allograft frequency, specificity, and phenotype of donor-reactive $T$ cell receptor (TCR) $\alpha \beta^{+}$and $\tau \delta^{+}$cells J Immunol 144 1288,1990

49 Miyaııma T, Higuchı R, Kashıwabara H, Yokoyama T, Fujimoto $S$ Anti-idiotypic antibodies in a patient with a functioning renal graft Nature 283 306, 1980

50 Suciu-Foca N, Reed E, Marboe C, Harris P, Pıng XI Y, Yu-Ka1 S, Ho E, Rose E, Reemtsma K, King DW The role of anti-HLA antibodies in heart transplantation Transplantation 51716,1989 